\title{
A new species of Palaemon from Cần Giớ District, Vietnam, previously confused with Palaemon sewelli (Kemp, 1925)
}

\author{
Christopher W. Ashelby, Sammy De Grave, Nguyên Van Xuân
}

\begin{abstract}
A new species of Palaemon is described from Cần Giớ District, Vietnam. This species has previously been reported from Vietnam as a colour morph of Palaemon sewelli (Kemp, 1925), to which it is clearly morphologically very closely related. However, the new species can be separated from $P$. sewelli through the position of the branchiostegal tooth relative to the branchiostegal groove, the shape of the suborbital lobe, a hirsute carapace and abdomen and the colour pattern of living individuals. The description of this new species brings the number of species of Palaemon known from Vietnam to eleven species.
\end{abstract}

LSID urn:lsid:zoobank.org:pub:71A2D71F-1D99-42FC-977D-156BF4825C80

Key words: Crustacea, Decapoda, Caridea, Palaemonidae

\section{Introduction}

The Palaemon fauna of Vietnam is well documented thanks to a series of publications by Nguyên (1992, 1997, 2000). In his account of the non-Macrobrachium Palaemoninae (Nguyên, 1992) five species of the genus were reported: Palaemon semmelinkii (De Man, 1881), P. concinnus, Dana, 1852, P. curvirostris Nguyên, 1992, P. serrifer (Stimpson, 1860), and P. pacificus (Stimpson, 1860). Subsequently, Nguyên (2000) reported a further species from Vietnam, Palaemon sewelli (Kemp, 1925), partially filling in a gap in its known distribution. Following the recent synonymy of Palaemonetes, Coutierella and Exopalaemon with Palaemon (De Grave \& Ashelby, 2013), a further four species can be added to this number, $P$. camranhi (Nguyên, 1997), $P$. sinensis (Sollaud, 1911), P. tonkinensis (Sollaud, 1914) and $P$. vietnamicus (Nguyên, 1992). Thus the reported Palaemon fauna of Vietnam currently stands at ten species.

In reporting $P$. sewelli from Vietnam, Nguyên (2000) noted the presence of two distinct colour morphs which occasionally co-oc- cur in a single catch: a white-tailed form and a dark-tailed form. However, despite a thorough examination, Nguyên (2000) concluded that only minor morphological differences were apparent between the two colour morphs, but stated that a further detailed study of the two morphs may yield interesting results. Specimens of both colour varieties reported by Nguyên (2000) were herein re-examined and the white-tailed colour morph is described as a new species.

The following abbreviations are used in the text: pocl (post-orbital carapace length), NHM (Natural History Museum, London), OUMNHZC (Oxford University Museum of Natural History Zoological Collection).

\section{Taxonomy}

Family Palaemonidae Rafinesque, 1815 Palaemon Weber, 1795

Palaemon leucurus sp. nov.

Figs. 1-4

LSID urn:lsid:zoobank.org:pub:71A2D71F1D99-42FC-977D-156BF4825C80 
Palaemon sewelli (nec Palaemon sewelli Kemp, 1925)—Nguyên, 2000 (partim).

Type material.-Holotype: ovigerous female, pocl. $6.1 \mathrm{~mm}$, coastal commune, Cần Giớ District, Vietnam, taken by conical set net, leg. Nguyên Van Xuân, 15.viii.2002, OUMNH. ZC.2017-01-67. Paratypes: 1 ovigerous female (dissected), pocl. $6.3 \mathrm{~mm}$, same collection data as holotype, OUMNH.ZC.2017-01-068; 6 ovigerous females, pocl. $5.5-7.2 \mathrm{~mm}$, same collection data as holotype, OUMNH.ZC.201110-008.

Comparative Material. Palaemon sewelli-1 male (pocl. $4.8 \mathrm{~mm}$ ), 2 females (pocl. 4.8, $6.8 \mathrm{~mm}$ ), 8 ovigerous females (pocl. 6.0 $7.5 \mathrm{~mm}$ ), coastal commune, Cần Giớ District, Vietnam, taken by conical set net, leg. Nguyên Van Xuân, 03.iii.1999, OUMNH.ZC.2011-10014; 5 specimens, Mormugao Bay, Portuguese India [present day Goa, India], coll. \& pres. Zoological Survey of India, det S. Kemp, NHM.1924.1.2.32.36

Description.-Carapace covered in short stiff setae (Fig. 1A). Rostrum (Figs. 1A-B, 4A-D) moderately slender, straight or slightly ascendant distally; approximately $0.78-0.92 \times$ carapace length, slightly overreaching scaphocerite; armed along entire length with 10-14 dorsal teeth and 3-4 ventral teeth; proximal dorsal teeth (sometimes all) with weakly constricted bases, posterior 3-5 teeth situated behind the orbit, proximal one situated just in front of middle of carapace, often spaced further apart than rest of series; spacing between remaining teeth roughly equal; rostral tip often appearing bifid due to small distal tooth; double row of setae present in between ventral teeth, distally sometimes only a single row. Antennal and branchiostegal teeth present; antennal tooth marginal, branchiostegal tooth set slightly back from margin (Figs. 1A, C). Branchiostegal groove originating dorsal to and re- moved from branchiostegal tooth (Figs. 1A, $1 \mathrm{C}, 4 \mathrm{E})$, trending downwards and finishing just in front of the mid-point of the carapace, slightly lower than insertion of branchiostegal tooth. Sub-orbital lobe (Figs. 1A, 1C, 4E) feebly produced; pterygostomial angle rounded. Béc ocellaire (Fig. 1A) globular, with strongly concave anterior margin, pronounced upwardly directed beak, dorsal surface with strong concavity.

Eye (Fig. 1G) well developed with pigmented cornea; cornea slightly wider than stalk but approximately equal in length; nebenauge present on dorsomesial side.

Antennular peduncle (Fig. 2A) extending to level of base of tooth of scaphocerite or falling slightly short of it; basal segment $2 \times$ as long as wide, convex outer margin, stylocerite acute; statocyst with statolith; distolateral tooth of basal segment far exceeding laminar portion; inner ventro-mesial tooth present; ultimate segment approximately equal in length to penultimate, their combined length being about two-thirds that of the basal segment; dorsal flagellum of the antennula (Fig. 2B) fused for about $0.15-0.20$ of its length (approximately 4-5 segments fused, 21-25 free); free portion with two aesthetascs on each segment.

Scaphocerite (Fig. 2C) broad, laminar, $1.8 \times$ as long as broad; outer margin straight, terminating in a tooth, falling short of distal margin of lamina; basal segment of antenna with large lateral tooth. Flagellum of the antenna about twice the length of the body.

Abdominal pleura furnished with plumose setae on ventral margin (Figs. 1D, 1E); fifth pleuron with posterodistal margin rounded; sixth segment is approximately $1.3 \times$ length of fifth; posterolateral margin (Fig. 1E) with small tooth and notch disto-ventrally; median lobe acute, with rounded ventral submedian process.

Mouthparts as described by Nguyen (2000) for $P$. sewelli and quite typical for the genus; mandible with palp three-segmented; third maxilliped reaching to middle of third segment 

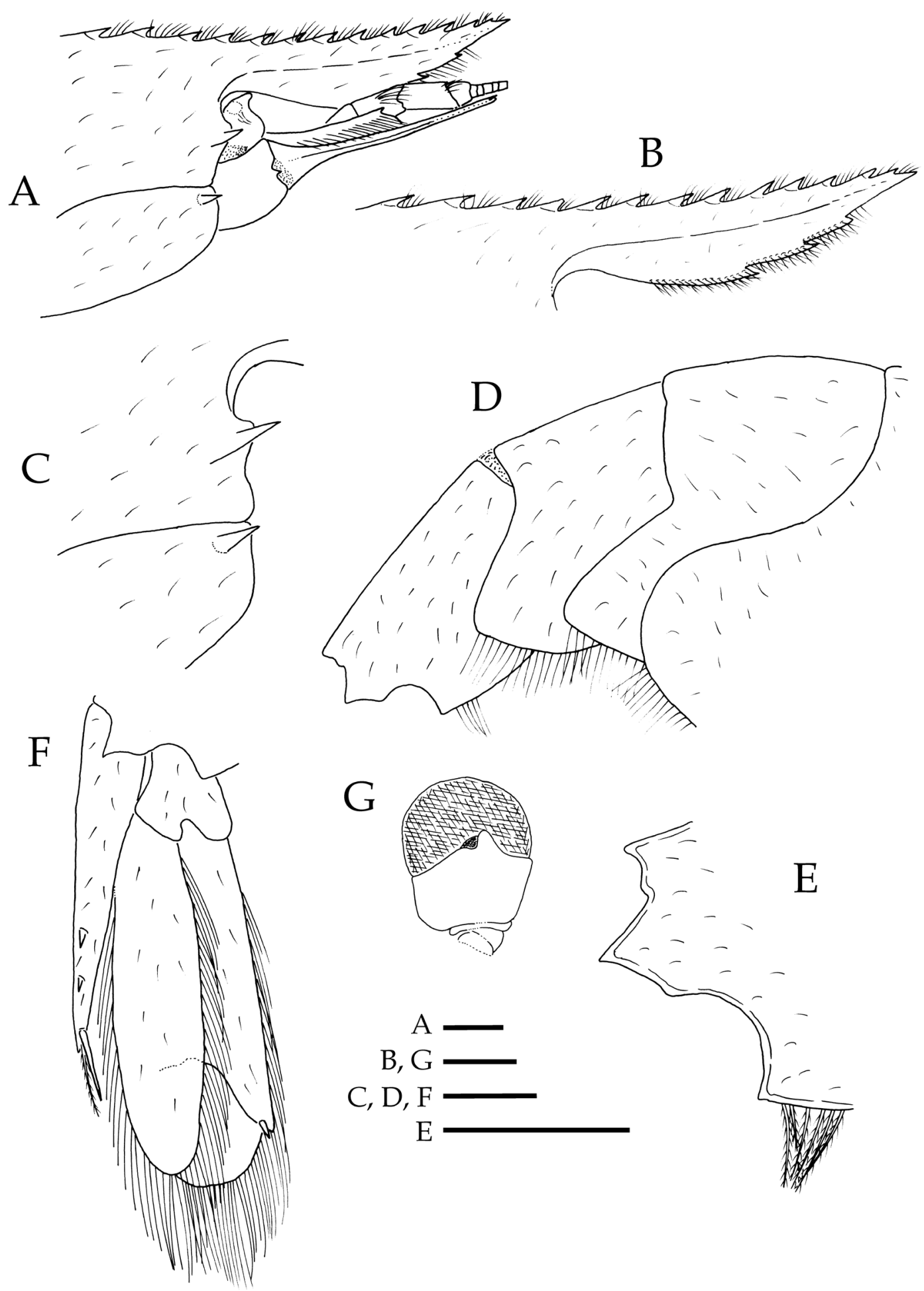

Fig. 1. Palaemon leucurus sp. nov. A) frontal region, lateral; B) rostrum; C) carapace, frontal margin; D) pleon, distal segments; E) sixth pleonite; F) tailfan; G) eye. All from ov. female holotype (OUMNH.ZC.2017-01-67, pocl 6.1 mm). Scale bars indicate $1 \mathrm{~mm}$. 


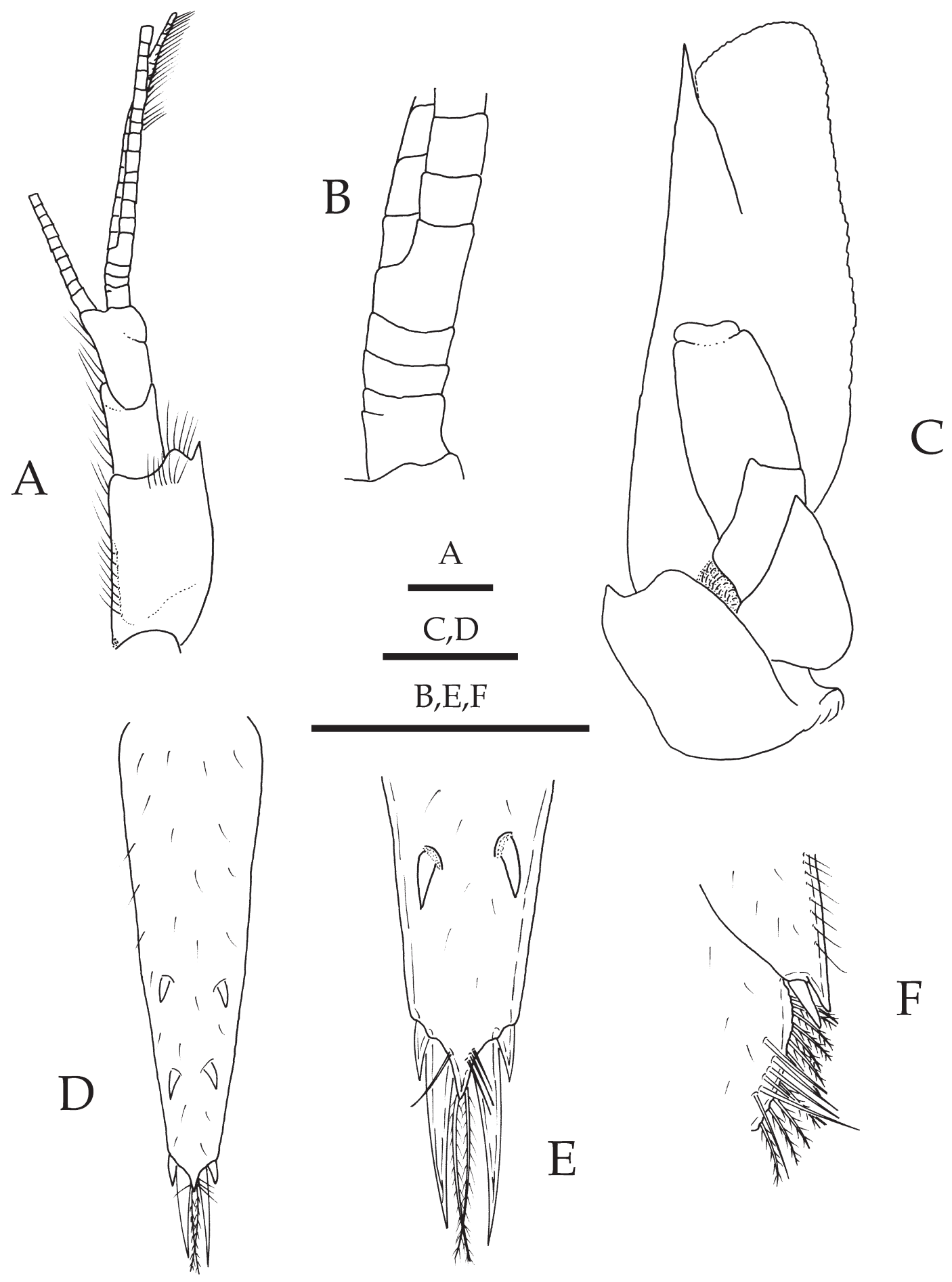

Fig. 2. Palaemon leucurus sp. nov. A) antennule; B) same, detail; C) antenna, scaphocerite; D) telson; E) same, tip; F) uropod, detail. All from ov. female paratype (OUMNH.ZC.2017-01-68, pocl $6.3 \mathrm{~mm}$ ). Scale bars indicate $1 \mathrm{~mm}$. 


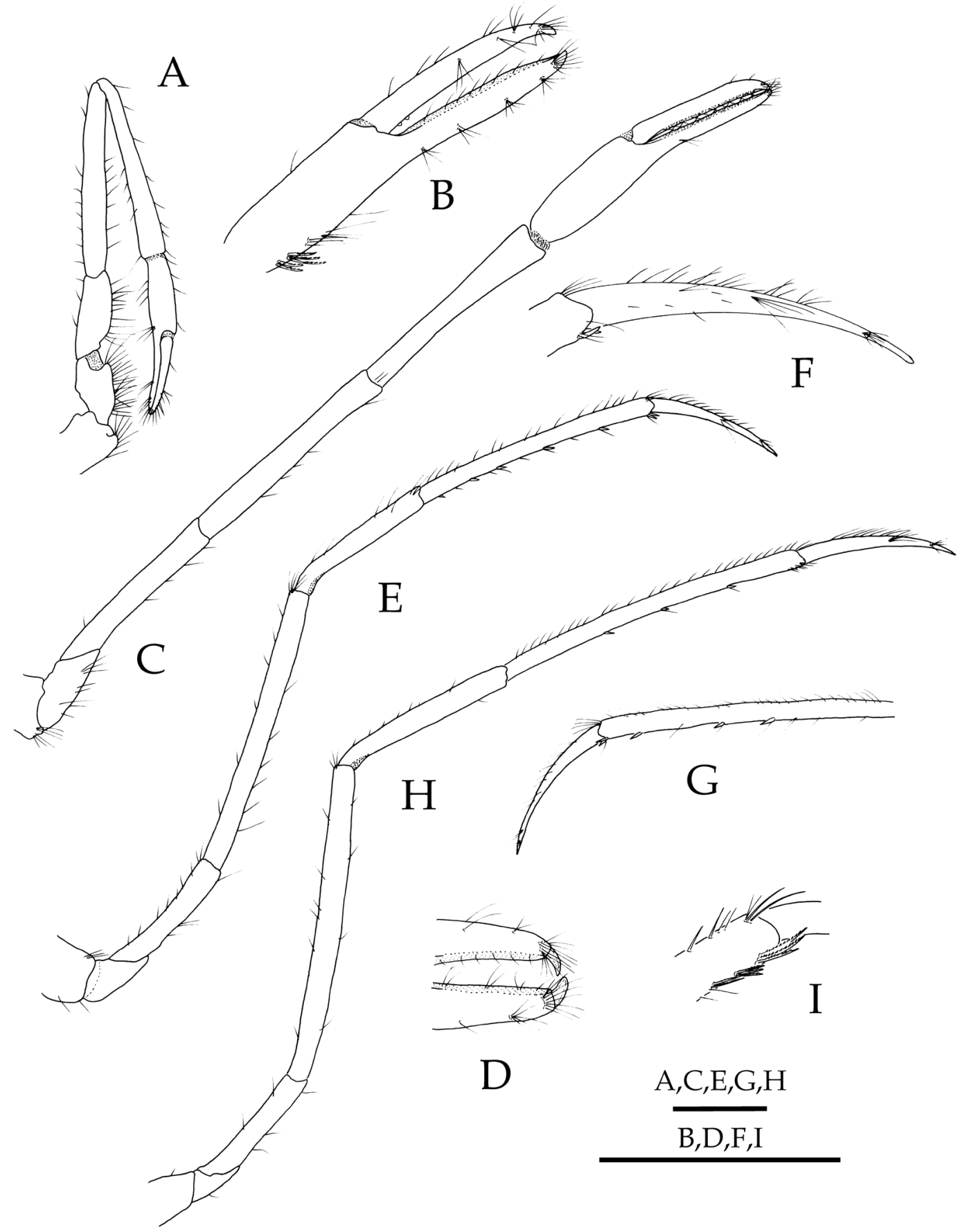

Fig. 3. Palaemon leucurus sp. nov. A) first pereiopod; B) same, chela; C) second pereiopod; D) same, chela, tip; E) third pereiopod; F) same, dactylus; G) fourth pereiopod, propodus and dactylus; H) fifth pereiopod; I) same, propodal brush. All from ov. female paratype (OUMNH.ZC.2017-01-68, pocl $6.3 \mathrm{~mm}$ ). Scale bars indicate $1 \mathrm{~mm}$. 
of antennular peduncle.

Well-developed pleurobranchs present on all pereiopods. First pereiopod (Fig. 3A) overreaches scaphocerite by whole length of chela; basis approximately equal to length of ischium; merus $2.5 \times$ length of ischium; carpus $0.9 \times$ length of merus; chela $0.85 \times$ length of carpus, fingers equal in length to palm, with tufts of setae; carpal-propodal brush well developed. Second pereiopod (Fig. 3C) extending beyond scaphocerite by approximately two-thirds of the propodus; ischium $2.0 \times$ length of basis; merus $1.1 \times$ length of ischium; carpus elongate, $0.9 \times$ of merus, expanded distally; chela about $1.3 \times$ length of carpus, fingers approximately equal in length to palm; moveable fin- ger proximally with two low, small teeth. Ambulatory pereiopods similar, moderately slender, increasing in length from third to fifth. Third pereiopod (Fig. 3E) over reaches scaphocerite by two-third of propodus; ischium $2.4 \times$ length of basis; merus $1.6 \times$ length of ischium; carpus $0.6 \times$ length of merus; propodus $1.5 \times$ length of carpus, slightly shorter than merus, ventral margin armed with 4-5 single cuspidate setae and a distal pair, dactylus (Fig. 3F) simple, slender, moderately curved, about half length of the propodus. Fourth pereiopod (Fig. $4 \mathrm{G}$ ) similar to third. Fifth pereiopod (Fig. $3 \mathrm{H}$ ) over reaching scaphocerite by about half length of propodus; ischium $1.8 \times$ length of basis; merus $2.4 \times$ length of ischium; carpus $0.6 \times$

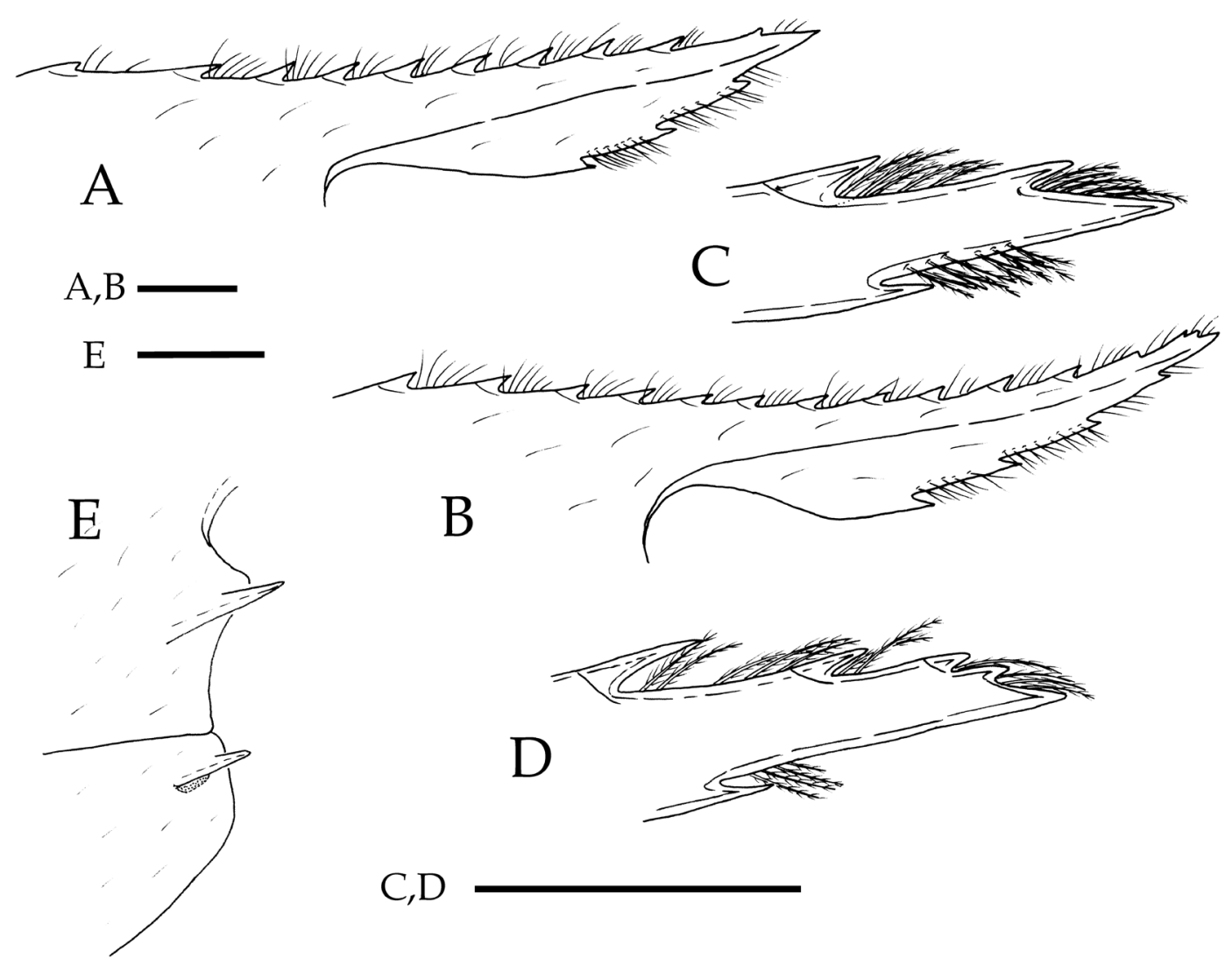

Fig. 4. Palaemon leucurus sp. nov. A) rostrum, ov. female, pocl $6.3 \mathrm{~mm}$; B) rostrum, ov. female, pocl $6.6 \mathrm{~mm}$; C) rostrum, tip, ov. female, pocl $6.3 \mathrm{~mm}$; D) same, ov. female, pocl $6.8 \mathrm{~mm}$; E) carapace, frontal margin. A-D, paratypes (OUMNH.ZC.2011-10-08); E, paratype (OUMNH.ZC.2017-01-68, pocl $6.3 \mathrm{~mm}$ ). Scale bars indicate $1 \mathrm{~mm}$. 
length of merus; propodus $1.7 \times$ length of carpus, ventral margin armed with 3-4 cuspidate setae, the distal most of which is paired, propodal grooming brush weakly developed (Fig. 3I) comprising 3 rows of 2-4 serrulate setae, extending for about $0.1 \times$ length of propodus; dactylus simple, slender, moderately curved, slightly less than half length of propodus.

Telson (Fig. 2D) about $1.4 \times$ sixth pleonite; length:width ratio $3.2: 1$ proximally narrowing to 10:1 distally; dorsal surface with two pairs of cuspidate setae and a few simple setae subdistally on median process (Fig. 2E); scattered short setae covering entire surface of telson; proximal dorsal tuft of setae present but easily abraded so frequently appearing absent; proximal pair of cuspidate setae situated at about 0.6 of telson length, distal pair at about 0.75 of telson length; marginal setae absent; posterior margin (Fig. 2E) prolonged into acute median process, with 1 pair of plumose setae and 2 pairs of stout setae, inner pair about $4 \times$ longer than outer pair; median process exceeding outer pair of stout setae.

Uropods broadly ovate, overreaching telson by $0.3 \times$ length of endopod (Fig. $1 \mathrm{~F}$ ); exopod slightly longer than endopod, weak diarhesis present; mobile distolateral seta of exopod overreaching fixed tooth by length of tip (Fig. 2F).

Colour pattern.-The colour pattern for Palaemon leucurus sp. nov. has been extensively described by Nguyên (2000: 189-190) and his comprehensive account is not reproduced here. The colour pattern is depicted in Fig. 6. The whitish colour of the sixth abdominal somite, telson and uropods and of the distal third of the rostrum, which contrasts strongly with the predominantly dark colouration of the remainder of the animal, is considered highly distinctive (Nguyên, 2000).

Distribution.-Currently only known with certainty from mangroves in Cần Giờ District,
South Vietnam.

Derivation of name.-From the Greek words leukos, white and oura, tail, referring to the white sixth pleonite, uropods and telson of the new species; used as a noun in apposition.

Remarks.-Palaemon leucurus sp. nov. is morphologically most similar to $P$. sewelli, under which name it was previously reported from Vietnam (Nguyên, 2000). In addition to the striking colour pattern differences (compare Figures 33-35 with Figure 1 in Nguyên, 2000 and Figure 6 herein), the main differences between the two species lie in the position of the branchiostegal groove in relation to the branchiostegal spine and in the development of the suborbital lobe, as well as the hirsuteness of the body (hirsute in P. leucurus sp. nov. vs lightly setose in $P$. sewelli). In P. leucurus the branchiostegal groove terminates above the branchiostegal tooth, whilst in $P$. sewelli it closely abuts. The suborbital lobe is well-developed in P. sewelli vs. much less so in P. leucurus, although there is some individual variation in this character in both species.

Nguyên (2000) described the body of $P$. leucurus sp. nov. (as P. sewelli "white-tailed colour-morph") as more hirsute than $P$. sewelli and this is confirmed in the present study. Several species of Macrobrachium are described as having a scabrous or hirsute carapace, although in general cuticular setae are comparatively rare in carideans and not reported in any other species of Palaemon, aside from $P$. sewelli sensu stricto (see Nguyên, 2000). However, these setae are easily overlooked and only visible under lateral directional light and are likely present in some other species of Palaemon at least, perhaps even not mentioned or illustrated as no taxonomic value has been accorded to this character within the genus. Such setae were not reported in other records of $P$. sewelli, including the original description (Kemp, 1925), although sparse setae were 
present on the specimens examined herein, from Vietnam and India (mainly abraded in the latter specimens due to their age). Caution should therefore be exercised in interpreting this character.

Kemp (1925) neither describes nor depicts the branchiostegal groove in his description of Palaemon sewelli, its terminus relative to the branchiostegal tooth is thus unclear. Based on the illustration, the suborbital lobe is well-developed. The opportunity is taken here to remedy this and the anterior margin and rostra of a number of Indian specimens of $P$. sewelli (NHM.1924.1.2.32.36) are illustrated herein (Figs. 5A-D) for comparison. In all specimens, including those from Vietnam (OUMNH.ZC. 2011-10-014), the branchiostegal groove terminates closely to the branchiostegal tooth, al- most abutting it in most cases, whilst the suborbital lobe is well developed.

In light of the recognition of $P$. leucurus sp. nov. previous literature records of $P$. sewelli were re-examined with the aim of elucidating the potential distribution of the new species. The record in Naiyanetr (2007) from Thailand contains no descriptive information and it is therefore not possible to determine whether this record refers to $P$. leucurus sp. nov. or $P$. sewelli sensu stricto. Jayachandran (2001) does not report any fresh material or new records and copies the illustrations in Kemp (1925). The specimens figured from Karachi (Pakistan) provided by Ghani (1999) show the definitive characteristics of $P$. sewelli, in terms of the terminus of the branchiostegal groove as well as the well-developed suborbital lobe. Liu et al.

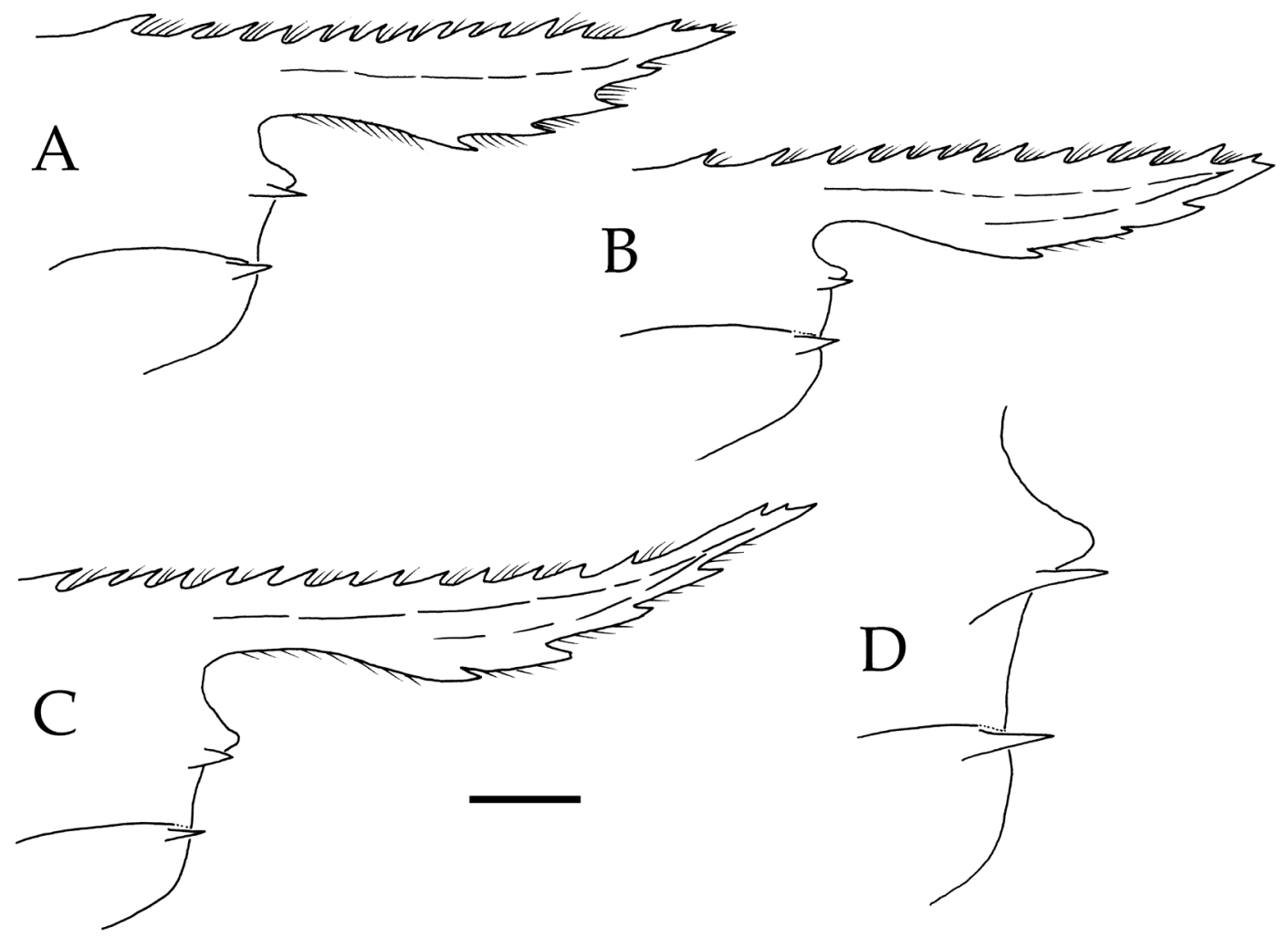

Fig. 5. Palaemon sewelli (Kemp, 1925), Mormugao Bay, Portuguese India, NHM.1924.1.2.32.36. A) frontal region, lateral (female, pocl $3.1 \mathrm{~mm}$ ); B) same (male, pocl $4.7 \mathrm{~mm}$ ); C) same (female, pocl $4.2 \mathrm{~mm}$ ); D) carapace, frontal margin (female, pocl $4.2 \mathrm{~mm})$. Scale bar indicates $1 \mathrm{~mm}(\mathrm{~A}-\mathrm{C})$ or $0.5 \mathrm{~mm}(\mathrm{D})$. 
(1990) and Li et al. (2007) apparently report upon the same records and the figure in the latter publication is reproduced from the earlier one. This figure indicates a lighter coloured stripe running along the dorsum and a laterally, darkly pigmented telson. The branchiostegal spine appears closely applied to the groove, although the development of the suborbital lobe is hard to observe. Based on these characters these reports are herein referred to $P$. sewelli. Li et al. (2004) report on a single female specimen of $P$. sewelli from Guangxi Province, southern China. Their colour description, "covered in small red dots on lateral surfaces, the dorsal surface from carapace to middle of telson with a whitish stripe", differs somewhat from that described by Nguyên (2000) for $P$. sewelli. A further specimen with a similar co- lour pattern is figured by Anker \& De Grave (2016) from Singapore as $P$. aff. sewelli. Since colour patterns are normally quite conservative in species of Palaemon, it is possible that the specimens from Guangxi and Singapore may represent a further undescribed species. Thus, at present, $P$. leucurus sp. nov. is only known with certainty from southern Vietnam.

Kemp (1925) mentioned four further localities in his description of Leander sewelli, additional to the type locality "Off Betim Point, opposite Nova Goa, Portuguese India” [present day Panaji, Goa, India]. Amongst these were six specimens with the following collection details "C864/1, above Cortalim, Mormugao Bay, Portuguese India, 1 1/2 fms. S. Kemp, Sept. 1916". In the Natural History Museum, London, there are five specimens with the follow-

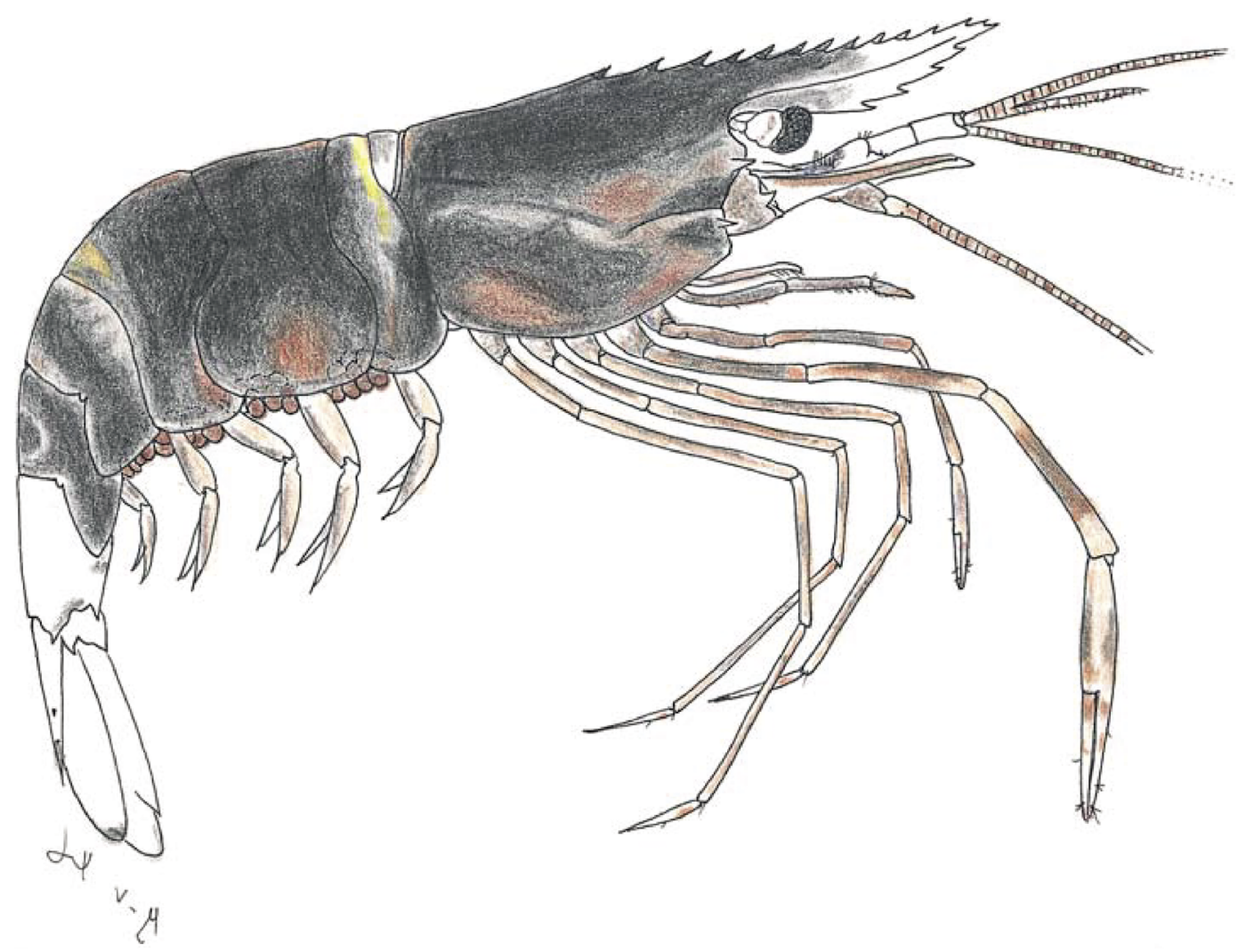

Fig. 6. Colour pattern of Palaemon leucurus sp. nov. (from Nguyên, 2000; with permission). 
ing details (herein examined) "Leander sewelli Kemp, 1925, Co-Types. Loc. Mormugao Bay, Coll. Zool. Survey of India, det. Kemp" (NHM 1924.1.2.32.36). Although labelled as co-types, the status of these specimens is here clarified. In view of the discrepancies in the number of specimens and the less specific location, it is clear that these would not be part of lot C864/1, which presumably was deposited in its entirety in the Calcutta Museum. It also seems unlikely that these specimens are part of the 52 specimens mentioned from the type locality in Kemp (1925), which is a different embayment somewhat further north than Mormugao Bay, and therefore, this lot (NHM 1924.1.2.32.36) is not considered to comprise syntypes. However, given the proximity to the type locality and the fact they were examined by Kemp, it is nonetheless clear that they represent the true Palaemon sewelli.

\section{Acknowledgements}

Paul Clark and Miranda Lowe (NHM) are thanked for providing facilities and the opportunity to examine the material of Palaemon sewelli. The authors would especially like to thank Zoologische Mededelingen for kindly providing permission to reproduce Fig. 6 in this paper which was originally published in by Nguyên (2000) as Figure 1 (Zool. Med. Leiden, 74: 182).

\section{Literature Cited}

Anker, A., \& De Grave, S., 2016. An updated and annotated checklist of marine and brackish caridean shrimps of Singapore (Crustacea, Decapoda). The Raffles Bulletin of Zoology, Supplement, 34: 343-454.

De Grave, S., \& Ashelby, C. W., 2013. A re-appraisal of the systematic status of selected genera in Palaemoninae (Crustacea: Decapoda: Palaemonidae). Zootaxa, 3734(3): 331344.
Ghani, N., 1999. Palaemon sewelli (Kemp, 1925): An addition to caridean fauna of Pakistan (Northern Arabian Sea). Pakistan Journal of Marine Biology, 5(2): 161-163.

Jayachandran, K. V., 2001. Palaemonid prawns. Biodiversity, taxonomy, biology and management. 624 pp. Science Publishers Inc., Enfield, New Hampshire, U.S.A.

Kemp, S., 1925. On various Caridea. Notes on Crustacea Decapoda in the Indian Museum, 17. Records from the Indian Museum, 27(4): 249-343.

Li, X., Bruce, A. J., \& Manning, R. B., 2004. Some palaemonid shrimps (Crustacea: Decapoda) from northern South China Sea, with descriptions of two new species. The Raffles Bulletin of Zoology, 52(2): 513-553.

Li, X., Liu, R., Liang, X. Q., \& Chen, G.-X., 2007. Fauna Sinica. Invertebrata vol 44. Crustacea Decapoda Palaemonoidea. 381 pp. Science Press, Beijing. [In Chinese]

Liu, J. Y., Liang, X. Q., \& Yan, S.-L., 1990. A study of the Palaemoninae (Crustacea Decapoda) from China II. Palaemon, Exopalaemon, Palaemonetes and Leptocarpus. Studia Marina Sinica, 31: 229-265. [In Chinese]

Naiyanetr, P., 2007. Checklist of crustacean fauna in Thailand (Decapoda, Stomatopoda, Anostraca, Myodocopa, Isopoda). 196 pp. Office of Natural Resources and Environmental Policy and Planning, Bangkok, Thailand.

Nguyên, V. X., 1992. Review of Palaemoninae (Crustacea: Decapoda: Caridea) from Vietnam, Macrobrachium excepted. Zoologische Mededelingen, 66: 19-47.

Nguyên, V. X., 1997. On a new species of prawn, Palaemonetes camranhi n. sp., from brackish water of South Vietnam (Decapoda, Caridea). Crustaceana, 70: 85-94.

Nguyên, V. X., 2000. Note on the occurrence of a rare palaemonid prawn, Palaemon sewelli (Kemp, 1925) in South Vietnam, with its description (Decapoda: Caridea). Zoologische Mededelingen, 74: 181-192. 


\section{Addresses}

(CA) APEM Ltd., Diamond Centre, Works Thu Duc District, Ho Chi Minh City, Vietnam.

Road, Letchworth Garden City. SG6 1LW.

United Kingdom.

(SDG) Oxford University Museum of Natural History, Parks Road, Oxford. OX1 3PW. United Kingdom.

(NVX) Faculty of Fisheries, Nông Lâm University (formerly The University of Agriculture \& Forestry), Linh Trung Ward,

\section{Email addresses}

$(\mathrm{CA})^{*}$ c.ashelby@apemltd.co.uk (SDG) sammy.degrave@oum.ox.ac.uk (NVX)nvxuan_uaf@yahoo.com.vn *corresponding author 